\title{
Pancreaticopleural Fistula: A Cause of Recurrent Pleural Effusions in Chronic Pancreatitis
}

\author{
Ayah Megahed ${ }^{1} \quad$ Rahul Hegde $^{1} \quad$ Pranav Sharma ${ }^{1}$ \\ ${ }^{1}$ Department of Radiology, Yale New Haven Health Bridgeport \\ Hospital, Bridgeport, Connecticut, United States
}

\author{
Rahmat Ali ${ }^{1} \quad$ Anas Bamashmos ${ }^{1}$
}

\begin{abstract}
Address for correspondence Rahul Hegde, MBBS, MD, DNB, FRCR, Department of Radiology, Yale New Haven Health Bridgeport Hospital, 267 Grant St, Bridgeport CT 06610, United States (e-mail: Rahul.hegde@yale.edu).
\end{abstract}

\begin{abstract}
Keywords

- pancreatitis

- chronic pancreatitis

- pancreaticopleural fistula

- recurrent pleural effusion

- MRCP

Pancreaticopleural fistula is a rare complication of chronic pancreatitis caused by disruption of the pancreatic duct and fistulous communication with the pleural cavity. It usually presents with respiratory symptoms from recurrent large volume pleural effusions. Paucity of abdominal symptoms makes it a diagnostic challenge, leading often to delayed diagnosis. Marked elevation of pleural fluid amylase, which is not a commonly performed test, is a sensitive marker in its detection. Imaging with magnetic resonance cholangiopancreatography and endoscopic retrograde cholangiopancreatography can help delineate the fistula. In this report, we present the clinical features, imaging, and management of a 59-year-old male patient with pancreaticopleural fistula, wherein the diagnosis was suspected only after repeated pleural fluid drainages were performed for re-accumulating pleural effusions and it was eventually successfully treated with pancreatic duct stenting. We review the literature with regards to the incidence, presentation, diagnosis, and management of this rare entity.
\end{abstract}

\section{Introduction}

Pancreaticopleural fistula (PPF) is a rare complication of chronic pancreatitis. It typically presents with dyspnea relating to pleural effusions, which in PPF can be high volume and rapidly re-accumulating. Owing to its rarity, and due to nonabdominal symptoms, diagnosis of PPF is often challenging as we highlight in our case below.

\section{Case Presentation}

A 59-year-old-male patient with past medical history of chronic obstructive pulmonary disease (COPD), heavy alcohol use, chronic pancreatitis with multiple episodes of superimposed acute pancreatitis, presented to our hospital with chief complaint of shortness of breath. Initial clinical suspicion was that this could be related to patient's COPD and patient underwent chest imaging. Chest radiograph and subsequent computed tomography (CT) chest imaging revealed bilateral pleural effusions with notably large and loculated effusions in the right chest and associated underlying lung consolidations ( - Fig. 1). An ultrasound-guided thoracentesis was done of the right chest with drainage of $1 \mathrm{~L}$ of serous fluid. The fluid analysis demonstrated $\mathrm{pH}$ of 7.34 , glucose of $127 \mathrm{mg} / \mathrm{dL}$, lactate dehydrogenase of $260 \mathrm{U} / \mathrm{L}, 4,000$ cells with $83 \%$ neutrophils. Cytology was negative for malignant cells. Patient was empirically treated with short course of antibiotics, till fluid culture was negative for growth. The patient's shortness of breath persisted, and a follow-up CT of the chest 5 days later showed persistent and increasing pleural fluid collections. Pulmonology service was consulted, and the patient underwent video-assisted thoracoscopic surgery (VATS) exploration, adhesiolysis, and evacuation of the right chest fluid collections with placement of three chest tubes. Patient improved symptomatically and was discharged. The patient then presented 10 days later again with shortness of breath, published online January 13, 2021
DOI https://doi.org/ $10.1055 / \mathrm{s}-0040-1719222$ ISSN 2581-9933.
(C)2021. Indian Society of Gastrointestinal and Abdominal Radiology. This is an open access article published by Thieme under the terms of the Creative Commons Attribution-NonDerivative-NonCommercial-License, permitting copying and reproduction so long as the original work is given appropriate credit. Contents may not be used for commercial purposes, or adapted, remixed, transformed or built upon. (https://creativecommons.org/licenses/by-nc-nd/4.0/).

Thieme Medical and Scientific Publishers Pvt. Ltd. A-12, 2nd Floor, Sector 2, Noida-201301 UP, India 
with CT showing enlarged right pleural effusion and a small left pleural effusion. During this admission, the gastroenterology service was also consulted, and they recommended repeat thoracentesis, with testing of pleural fluid amylase and lipase to rule out a possible pancreatic etiology. Pleural effusion analysis was sent and revealed markedly elevated amylase $(>7,500 \mathrm{U} / \mathrm{L})$, elevated lipase $(>3,000 \mathrm{U} / \mathrm{L})$ raising the possibility of a pancreatic-pleural fistula. Magnetic resonance imaging (MRI) of the abdomen and magnetic resonance cholangiopancreatography (MRCP) with secretin injection was performed. The study demonstrated a T2 hyperintense fistula tract communicating with the pancreatic duct in the body of the pancreas on its posterior aspect, with continuation superiorly into the chest through the esophageal hiatus, branching and communicating with both the pleural spaces. The dominant fistula tract extended to the right pleural cavity (-Figs. 2 and 3, - Video 1). ERCP confirmed the diagnosis and provided treatment with bridging of the pancreatic duct defect with a stent ( - Fig. $\mathbf{3 b}$ ). Patient was also treated medically with octreotide to improve chances of duct healing by reducing volume of pancreatic secretion. The patient's shortness of breath improved, with resolution of the pleural

\section{Video 1}

This cine video clip with T2 weighted sequence from MRI abdomen study demonstrates fistula tract (arrows) seen extending from the pancreatic duct and extending to the pleural space. Online content including video sequences viewable at: https://www.thieme-connect. com/products/ejournals/ html/10.1055/s-0040-1719222.

effusions on follow-up. The chest tubes were removed, and the patient was discharged. On 1 year clinical and imaging follow-up, the patient remained symptom free.

\section{Discussion}

PPF is a rare complication of chronic pancreatitis. ${ }^{1}$ It occurs in $0.4 \%$ of cases with pancreatitis ${ }^{2}$ and in $4.5 \%$ in patients with a pancreatic pseudocyst. ${ }^{3}$ Pleural effusion
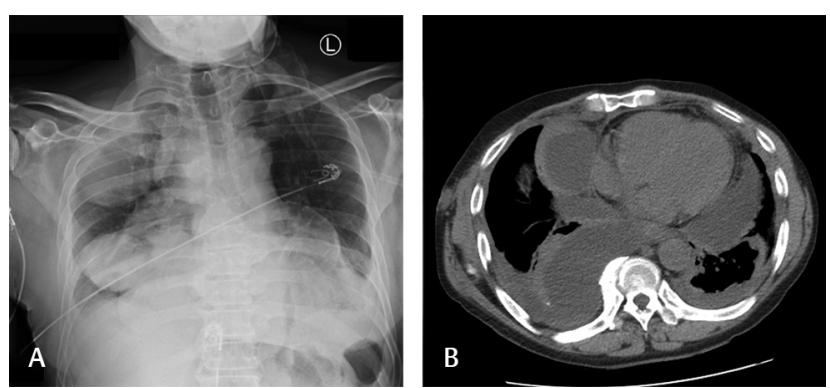

Fig. 1 Chest radiograph (A) and axial noncontrast CT chest (B) demonstrate bilateral pleural effusions, larger and loculated on the right. in cases with PPF is high volume and rapidly re-accumulating. ${ }^{4}$ Owing to its rarity, and with confounding medical causes, diagnosis of PPF is often delayed, which happened in our case that needed repeated pleural fluid drainages. It is classically diagnosed in middle-aged, predominantly male patients, with chronic pancreatitis related mainly to alcohol abuse. ${ }^{5}$ Clinical presentation of PPF varies between patients according to the level of pancreatic injury and the amount of fluid in the pleural cavity. Our case presented with shortness of breath, which is the most common presenting symptom (65\%) in cases with PPF. ${ }^{5}$ The most likely pathogenesis of PPF is from posterior leakage of an incompletely formed pseudocyst or rupture of a mature one and subsequent formation of a tract that communicates
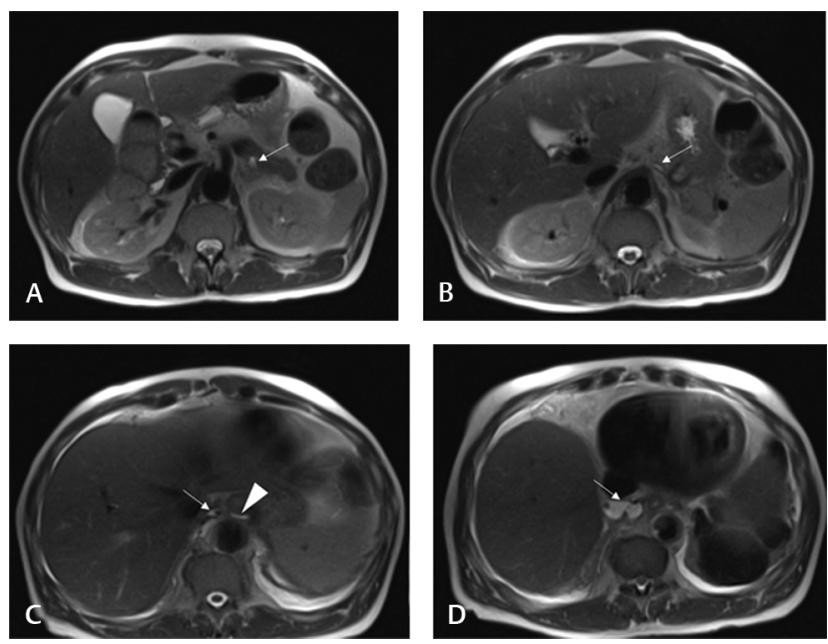

Fig. 2 Serial T2-weighted images (caudal to cranial A-D) from MRI abdomen/MRCP study demonstrate the course of the pancreatic pleural fistula (white arrow) extending from the pancreatic duct in the body of the pancreas, coursing through the diaphragmatic hiatus to the right pleural space. Bifurcation of the tract with another tract extending to the left pleural space is also noted (arrowhead in $\mathbf{C}$ ).
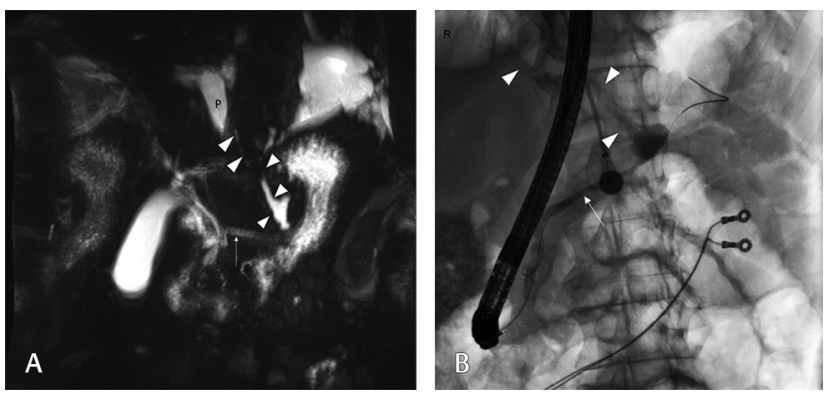

Fig. 3 MIP image from MRCP (A) and ERCP fluoroscopic image (B) before pancreatic duct stenting demonstrate a curvilinear pancreatic pleural fistula (arrowheads) extending from the pancreatic duct (arrow) toward the right pleural space (annotated letter $P$ on image A). ERCP, endoscopic retrograde cholangiopancreatography; MIP, maximum intensity projection; MRCP, magnetic resonance cholangiopancreatography. 
the pancreatic duct with the pleural space. ${ }^{4,6}$ The fistula courses along the retroperitoneum, traverses across aortic or esophageal hiatus or rarely via transdiaphragmatic route, and finally tracks into the pleural space, $76 \%$ times in the left pleural cavity, $19 \%$ on the right, or $14 \%$ in both pleural spaces. ${ }^{2,4}$

Diagnosis of PPF is challenging, owing to its rarity, and a high level of suspicion is required. Our case presented with shortness of breath, which is a typical presentation for a PPF, yet that was attributed initially to a pulmonary etiology. He had bilateral pleural effusions, more on the right side, for which he underwent multiple thoracentesis, chest tube insertions with re-accumulation of the pleural effusion. His hospital stays which spanned several days was concluded with VATS exploration, and multiple chest tube insertions, after he was discharged, yet to present again 10 days later with dyspnea due to recurrent pleural effusions. This morbidity and repeated interventions could have been mitigated if the PPF could have been diagnosed earlier. Elevated pleural fluid amylase is the single most important diagnostic clue, in the proper clinical setting and should be promptly tested in initial disease course for early detection. The level of pleural fluid amylase is generally above $1,000 \mathrm{U} / \mathrm{L}$, although there is no threshold value, and it is not solely specific to PPF. ${ }^{5,7}$ If positive, this should be followed by imaging to depict the course of the fistula.

Compared with CT, MRI and MRCP, particularly with secretion injection is more sensitive and is the imaging modality of choice for diagnosis of PPF$^{5}$; it not only shows the parenchymal abnormalities in the pancreas and depicts the fistulous track, but it also depicts the pancreatic duct distal to the fistula, allows its assessment and hence can stratify patient management. ${ }^{8}$ ERCP can diagnose the PPF and has an added therapeutic advantage of performing stenting to exclude the fistula from the pancreatic duct, as was done in our patient.

Wronski et al described management of PPF based on the anatomy of the pancreatic duct as shown by MRCP. ${ }^{7}$ Patients with relatively normal or mildly dilated duct benefit the most from medical therapy, with octreotide, which is a somatostatin analogue that decreases the pancreatic succus, reducing the fistula output and shortening the time to closure, in addition to drainage of the pleural effusion. Endoscopic stenting of the duct defect causes a mechanical obstruction to the communication between the duct and the fistula, in cases with disruption of the duct at the pancreatic head and body, yet the success depends on technical expertise. ${ }^{9}$ Surgical management is reserved for cases with failed medical or endoscopic management, especially in cases with severe pancreatic duct strictures and multiple pseudocysts. $^{10}$

\section{Conflict of Interest}

None declared.

\section{References}

1 Materne R, Vranckx P, Pauls C. Coche EE, Deprez P, Van Beers BE. Pancreaticopleural fistula: diagnosis with magnetic resonance pancreatography. Chest 2000;117(3):912-914

2 Sut M, Gray R, Ramachandran M, Diamond T. Pancreaticopleural fistula: a rare complication of ERCP-induced pancreatitis. Ulster Med J 2009;78(3):185-186

3 Olakowski M, Mieczkowska-Palacz H, Olakowska E, Lampe P. Surgical management of pancreaticopleural fistulas. Acta Chir Belg 2009;109(6):735-740

4 King JC, Reber HA, Shiraga S, Hines OJ. Pancreatic-pleural fistula is best managed by early operative intervention. Surgery 2010; 147(1):154-159

5 Ali T, Srinivasan N, Le V, Chimpiri AR, Tierney WM. Pancreaticopleural fistula. Pancreas 2009;38(1):e26-e31

6 Vyas S, Gogoi D, Sinha SK, Singh P, Yadav TD, Khandelwal N. Pancreaticopleural fistula: an unusual complication of pancreatitis diagnosed with magnetic resonance cholangiopancreatography. JOP 2009;10(6):671-673

7 Wronski M, Slodkowski M, Cebulski W, Moronczyk D, Krasnodebski IW. Optimizing management of pancreaticopleural fistulas. World J Gastroenterol 2011;17(42):4696-4703

8 RockeyDC,CelloJP.Pancreaticopleuralfistula.Reportof7patients and review of the literature. Medicine (Baltimore) 1990; 69(6):332-344

9 Safadi BY, Marks JM. Pancreatic-pleural fistula: the role of ERCP in diagnosis and treatment. Gastrointest Endosc 2000; 51(2):213-215

10 Aswani Y, Hira P. Pancreaticopleural fistula: a review. JOP 2015;16(1):90-94 